\title{
Arquitetura rural: Arranjo físico e paisagístico da cafeicultura na Fazenda Vidigal
}

\author{
Rural architecture: Physical and landscape of coffee arrangement production at Fazenda Vidigal \\ Arquitectura rural: Ordenación física y paisajística de la producción de café en Fazenda Vidigal
}

Recebido: 09/06/2021 | Revisado: 17/06/2021 | Aceito: 20/06/2021 | Publicado: 24/06/2021

\author{
Alline Maria Trancoso Ferraz Silva David \\ ORCID: https://orcid.org/0000-0003-4860-3946 \\ Universidade Estadual do Sudoeste da Bahia, Brasil \\ E-mail: allinetrarquitetura@gmail.com \\ Jerisnaldo Matos Lopes \\ ORCID: https://orcid.org/0000-0002-3921-3631 \\ Universidade do Estado da Bahia, Brasil \\ E-mail: jerislopes@hotmail.com
}

\begin{abstract}
Resumo
Desde o período neolítico onde o homem percebeu que podia transformar a paisagem natural e se sedentarizar, que o bionegócio tem marcado intensamente a ação antrópica no meio natural. A produção de alimentos iniciou como fonte de sobrevivência e, a posteriori, com a descoberta e introdução das técnicas, houve um avanço no cultivo que passou a ser maior que o suficiente para o autoconsumo. Neste contexto, a pesquisa faz uma abordagem histórica sobre a implantação paisagística das fazendas de café, que possui grande relevância econômica para o país, maior produtor de grãos beneficiados do mundo. Nessa perspectiva, o objetivo do presente estudo é compreender o arranjo físico e paisagístico da implantação da lavoura cafeeira na Fazenda Vidigal em Barra da Choça, BA, na tentativa de identificar os avanços tecnológicos abrangendo as instalações, equipamentos e pessoas envolvidas. Trata-se de um estudo qualitativo e para localizar a propriedade e descrever a estrutura espacial de uma fazenda de café foram utilizados cruzamento de informações de análise bibliográfica exploratória e pesquisa de campo. Tais arranjos promovem o constante desenvolvimento da lavoura cafeeira em uma região de destaque no cenário Nacional e internacional pela qualidade do café, peculiaridade do seu plantio, cultivo, produção, colheita, até a exportação.
\end{abstract}

Palavras-chave: Arquitetura paisagística; Agronegócio; Café; Coffea arabica.

\begin{abstract}
Since the neolithic period, when man realized that it could transform the natural landscape and become sedentary, that the Bio business has intensively marked an anthropic action in the natural environment. Food production started as a source of survival, after then, with the introduction and discovery of new technics there was an advancement in cultivation, which generated more than enough for self-consumption. In this context, the research has done a historical approach to coffee implantation, which is very important to the country, the biggest coffee bean production in the world. In this perspective, the purpose of this study is to understand the physical and landscape coffee arrangement production at Fazenda Vidigal, in Barra do Choça, BA, trying to identify the technological advance and the facilities, equipment and people involved. This is about a qualitative study to locate the property and describe the spatial structure of a coffee farm. It was used crossed information of exploratory bibliographic analysis and field research. These arrangements further the constant development of coffee farming at a prominent region in the national and international scenery because of the coffee quality, unique way to plant, farm, production, harvest, until the exportation.
\end{abstract}

Keywords: Landscape architecture; Agribusiness; Coffee; Coffea arabica.

\section{Resumen}

Desde el Neolítico, cuando el hombre se dio cuenta de que podía transformar el paisaje natural y volverse sedentario, la bioempresa ha marcado intensamente la acción antrópica en el medio natural. La producción de alimentos comenzó como una fuente de supervivencia y, a posteriori, con el descubrimiento e introducción de técnicas, se produjo un avance en el cultivo que se volvió mayor que suficiente para el autoconsumo. En este contexto, la investigación toma un enfoque histórico sobre la implantación paisajística de las fincas cafeteras, lo que tiene una gran relevancia económica para el país, el mayor productor de granos procesados del mundo. En esta perspectiva, el objetivo del presente estudio es comprender la disposición física y paisajística de la implantación de la plantación de café en la Fazenda Vidigal en Barra da Choça-Bahia, en un intento por identificar los avances tecnológicos que abarcan las instalaciones, los equipos y las personas involucradas. Se trata de un estudio cualitativo y para ubicar la propiedad y describir la estructura espacial de una finca cafetera se utilizó información cruzada de análisis bibliográfico exploratorio e investigación de campo. Dichos arreglos promueven el desarrollo constante de la caficultura en una 
región de protagonismo en el panorama nacional e internacional por la calidad del café, peculiaridad de su siembra, cultivo, producción, cosecha, hasta la exportación.

Palabras clave: Arquitectura del paisaje; Agronegocios; Café; Coffea arabica.

\section{Introdução}

O presente artigo é fruto da dissertação de mestrado que aborda a arquitetura rural no estudo do arranjo físico e paisagístico da cafeicultura, agronegócio de grande importância comercial. O interesse deste trabalho é criar conteúdo relevante e dialogar com outros pesquisadores interessados por este recorte temático.

As ocupações humanas mais primitivas iniciaram a transformação da paisagem natural com o surgimento da agricultura no período Neolítico, cerca de 10.000 a.C. As práticas agrícolas são fundamentais para que o homem se organize em grupos, por meio delas, os alimentos são produzidos nas mais distintas regiões do mundo. Com a descoberta de ferramentas e técnicas de manejo na ocupação do solo, houve significativos avanços nas interferências antrópicas e a produção agrícola se intensificou, haja vista que as cidades se formaram e evoluíram até os dias atuais ávidas por sustentabilidade.

Além da questão da sustentabilidade, outros aspectos merecem atenção de especialistas, para estruturar, sempre em paralelo e diálogo com o poder político e econômico, os espaços urbanos e rurais. O desenho e construção do território, com o passar dos dias e organização das cidades, tem sido confiado nas mãos de Arquitetos Paisagistas, Arquitetos Urbanistas e Engenheiros, os quais integram o conjunto daqueles a quem legitimamente é atribuída essa missão.

Baseado nos os estudos de Slack, Chambers e Johnston (2002), o arranjo físico é uma ferramenta de melhoria que influência o desempenho da organização, preocupa-se com o posicionamento físico, interferindo diretamente nas atividades de produção. Assim, como na arquitetura de uma edificação resolver o fluxo da paisagem de uma lavoura pode ser crucial para o desempenho apropriado da produção.

Como a arquitetura rural pode ser estudada no arranjo físico e paisagístico da fazenda Vidigal, no município de Barra da Choça, BA, considerando que projeto paisagístico é um processo gráfico que visa encontrar uma solução espacial lógica, integrada e harmoniosa que entenda os objetivos, expectativas e necessidades dos usuários do espaço e que respeite e considere as características do local onde está implantado.

Neste sentido, na Arquitetura Paisagística Urbana e Rural, espécies nativas ou não, das mais diferentes classes de plantas têm sido empregadas para compor diversas paisagens. Assim, a análise do arranjo físico e o projeto paisagístico possibilitam avaliar qualitativamente e integrar as soluções encontradas através dele é possível estabelecer relações entre os vários espaços, a quantificação de insumos, mudas e levantamento dos custos da implantação de qualquer agronegócio.

A análise transcorre da implantação cafeeira na Fazenda Vidigal, localizada no município de Barra do Choça, que está localizada a $524 \mathrm{~km}$ da capital Salvador, BA. O município possui aproximadamente $900 \mathrm{~m}$ de altitude e características edafoclimáticas adequadas para produção do café (Coffea arabica) com qualidade.

A presente pesquisa visa despertar o interesse por conhecer a propriedade, a qual se constitui como uma referência da arquitetura paisagística rural, cultural, científica e retrata a história da implantação do café na região, além dos proprietários se envolverem de forma direta, por meio do Encontro Nacional do Café, com o fomento, a pesquisa e disseminação do conhecimento da cultura cafeeira a nível mundial. Portanto, a pesquisa é relevante do ponto de vista acadêmico e social, haja vista que se trata de oportunidade de dar visibilidade à propriedade situada em município de pequeno porte e ainda o empenho em conhecer e divulgar as técnicas e conhecimentos utilizados na referida propriedade rural, despertou o interesse pelo objeto de estudo e contribuiu para definição do Lócus.

Deste modo, as discussões presentes nesta pesquisa têm o objetivo de identificar no âmbito da arquitetura rural, o arranjo físico e paisagístico os da implantação cafeeira na região sudoeste da Bahia, a partir da análise da Fazenda Vidigal. 


\section{Metodologia}

No presente estudo, os procedimentos técnicos utilizados foram pesquisa bibliográfica exploratória com abordagem qualitativa que em geral, ocorre no ambiente natural com coleta direta de dados descritivos e o pesquisador é o principal agente e através da pesquisa de campo. A revisão de literatura e a observação de campo foram fundamentais para embasar o arranjo físico e paisagismo da cafeicultura e entender o que os demais autores abordam a cerca da arquitetura rural (Pereira, et al, 2018).

Para tanto, foi realizada a revisão da literatura, que se constitui como um processo de busca, análise e descrição de um corpo do conhecimento em busca de resposta a uma pergunta específica. Nos livros e artigos, foram encontrados diferentes tipos de estudos que embasaram esta pesquisa, a qual é de natureza exploratória com abordagem qualitativa. Alguns estudos que embasaram a construção da pesquisa foram: Argollo Ferrão (2004); Nova (2010); Matsumoto (et al., 2003); Rocha (2011); Slack, Chambers e Johnston (2002); Benincasa e Farah (2020); (Kohlhepp, 2020).

O estudo de campo foi realizado com visitas à propriedade rural e segundo pesquisas na literatura esse estudo foi escolhido por caracterizarem-se pelas investigações que priorizam estudar as questões norteadoras da distribuição das propriedades da população segundo determinadas variáveis, usando muito mais artifícios de observação do que perguntas (Gil, 2010).

A observação de campo foi realizada na Fazenda Vidigal, BA que fica a $900 \mathrm{~m}$ de altitude, em uma região com clima tropical de altitude e possui área de 146 hectares, sendo destes 105 ha com cultivo da cultura do café. É nesse cenário que a propriedade forma um complexo de paisagem cultural compondo o patrimônio histórico da cidade de Barra do Choça, uma cidade situada no interior da Bahia, na região Sudoeste do Estado, como evidenciado na Figura 1. Ao longo dos anos a fazenda foi se transformando em um cenário de fomento a cultura, pesquisa e arte, além de ser um importante campo produtivo cafeeiro.

Figura 1 - Localização da área da pesquisa.

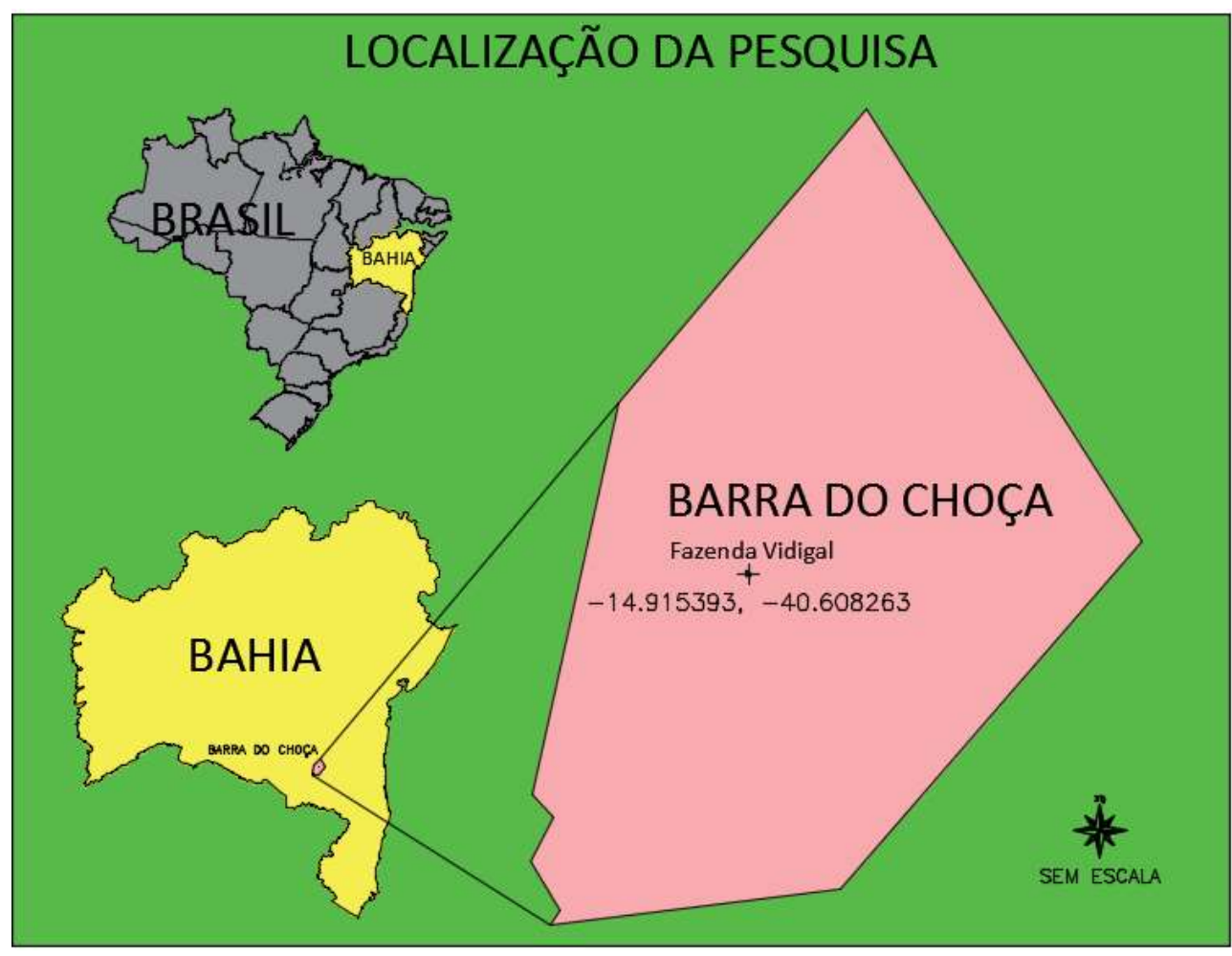

Fonte: Autores (2020). 
Com relação à população estimada, segundo dados do Instituto Brasileiro de Geografia e Estatística (IBGE) em 2020 era de 34.788 habitantes. A área do município é de 765,936 km² e foi desmembrada de Vitória da Conquista, pela Lei Estadual $\mathrm{n}^{\circ} 1.694$, de 22 de junho de 1962 e instalado em 7 de abril de 1963. No que se refere aos municípios limítrofes destacam-se Vitória da Conquista, Planalto, Caatiba e Itambé (IBGE, 2020).

$\mathrm{Na}$ etapa de pesquisa de campo, aconteceram duas visitas as fazendas, a fazenda Vidigal, a primeira oportunidade foi no Encontro Nacional do Café, realizado em maio de 2019, momento em que foram observados elementos fundamentais para maior compreensão da implantação da lavoura e a sua relação com as características edafoclimáticas e na segunda visita foi possível analisar os diversos talhões da lavoura, seu distanciamento, os elementos arquitetônicos que compõem a propriedade e a logística do processo produtivo. A análise dos resultados foi feita por meio da revisão de literatura em paralelo com as observações realizadas embasado os resultados da referida pesquisa.

\section{Resultados e Discussão}

O fruto do cafeeiro é uma importante commodity tanto no comércio nacional como a nível internacional, sendo o Brasil o maior exportador do grão. Dentre as espécies existentes, a Coffea arabica e Coffea canephora são as de maior relevância econômica e a região de Barra do Choça possui características ambientais favoráveis para o plantio do café arábica com qualidade (Peruzzolo et al 2019).

O início da produção do café no Brasil foi marcado pelas dificuldades com a mão de obra e com a falta de conhecimentos agrícolas sobre o plantio de beneficiamento do grão, fatores que são de fundamental importância para determinar a manutenção, a qualidade e, consequentemente, o valor de mercado do agronegócio cafeeiro (Vianna, 2020).

A cultura do café ocupou vales e montanhas, viabilizando o aparecimento de cidades e dinamização de importantes centros urbanos por todo o interior do Estado de São Paulo, sul de Minas Gerais e norte do Paraná. Ferrovias foram construídas, substituindo o transporte animal e possibilitando o rápido escoamento da produção. O café atraiu um grande número de imigrantes, consolidou a expansão da classe média e a diversificação de investimentos. A procura pela região ideal para a lavoura cafeeira se estendeu por todo o país, se firmando hoje em regiões do Estado de São Paulo, Minas Gerais, Paraná, Espírito Santo, Bahia e Rondônia. O café continua hoje, a ser um dos produtos mais importantes para o Brasil, sendo o país o primeiro produtor mundial do produto (Nova, 2010).

$\mathrm{O}$ arranjo físico refere-se ao posicionamento de máquinas, equipamentos e pessoas, nos cafezais compreende a distribuição dos renques, localização das máquinas e organização espacial da fazenda, sendo esse um artifício decisivo para que a lavoura consiga operar com o mínimo de desperdício e maior eficácia. O layout adequado de um negócio pode proporcionar o aumento da produtividade e um ambiente laboral apropriado para os servidores que resultará na satisfação da equipe de trabalho, podendo minimizar as despesas e consequentemente maior lucro.

O arranjo físico é classificado em quatro tipos, segundo classificação de Slack, Chambers e Johnston (2002):

- Arranjo Físico por Processo: onde os processos parecidos se localizam próximo para aperfeiçoar a atividade por diminuir as distâncias percorridas;

- Arranjo Físico Celular: o produto que será transformado é pré-selecionado e se movimenta até onde será operacionalizado;

- Arranjo Físico Por Produto: nessa situação os recursos transformadores estão locados em série por tipologia;

- Arranjo Físico Posicional: o produto a ser transformado não se movimenta entre os recursos transformadores. Os maquinários e pessoas, como exemplo temos o canteiro de obras na arquitetura e no nosso objeto de estudos, a colheita na lavoura de café.

Com relação ao comportamento econômico o desenvolvimento da agricultura atrai levas de imigrantes que vem para 
as regiões das fazendas a procura de trabalho e isso gera uma influência direta na arquitetura, refletindo nas novas fronteiras agrícolas abertas essa migração acarretaria em mudanças profundas na arquitetura praticada, novas residências surgem, ajustes são feitos nas fazendas para acomodar o crescimento do maquinário e da equipe, habitantes com diferentes influências arquitetônicas dos seus locais de origem (Benincasa, 2007).

De acordo, com as leituras acerca da cafeicultura foi possível constatar que assim como na região de Barra do Choça, os condicionantes ambientais que favorecem a cultura do Coffea arabica impulsionaram a cultura cafeeira e por consequência estimularam a migração. Devido a existência de solo adequado, condições morfológicas adequadas e altitude propícia, o avanço da cultura cafeeira necessita de mão de obra e assim, consequentemente promove uma forte migração, contribuindo para o crescimento da população rural em regiões de forte desenvolvimento da cafeicultura como Minas Gerais e São Paulo (Kohlhepp, 2020).

A implantação da lavoura cafeeira, em 1972 foi um aspecto marcante relacionado à expansão da cidade de Barra do Choça havendo um aumento populacional, vez que a implantação das fazendas necessitava de mão de obra para a derrubada das matas, o preparo do solo e o plantio do café. Essas pessoas que chegaram a Barra do Choça, nesse período, vinham de diversas localidades, tanto de cidades próximas, como Vitória da Conquista e das demais cidades da Região Sudoeste, como também houve a chegada de imigrantes italianos fugitivos da guerra, que, aos poucos, foram ocupando a cidade e, através de concessões do governo, tomavam posse das terras do município (Rocha, 2011).

É importante destacar que a organização das cidades segue diretrizes ou previsões legais. O Estatuto das Cidades, Lei n. 10.257/2001, regulamentado pela constituição federal, estabelece diretrizes gerais da política urbana. No que concerne ao Plano Diretor, o capítulo III da referida lei, o conceitua como o instrumento básico da política de desenvolvimento e de expansão urbana; no mesmo sentido, o art. 41 prevê que "o plano diretor é obrigatório para cidades: com mais de vinte mil habitantes" (Brasil, 2001).

Desde os primórdios, quando se trata da formação dos povos e a sedentarização dos homens, que se observa a importância da tecnologia para o crescimento da produção agrícola, com consequente crescimento populacional e formação das cidades. Com Barra do Choça não foi diferente. O município é amplamente influenciado pelo desenvolvimento da cultura cafeeira que estimulou a chegada de pessoas de diversos lugares, promoveu o crescimento populacional e impulsionou a urbanização da cidade. Assim, segundo as regras do Art. $41^{\circ}$ do Estatuto das Cidades, Barra do Choça ganhou um plano diretor urbano e código de obras que é um documento com diretrizes importantes para o trabalho dos Arquitetos e Engenheiros, em consonância com o poder público.

A arquitetura rural de uma fazenda de café abrange o complexo arquitetônico constituído pelo terreiro, casa das máquinas e pelo arranjo paisagístico da lavoura e a arquitetura das construções existentes na maior parte das propriedades rurais produtoras de café envolvendo os currais, almoxarifados, escritórios, casas de trabalhadores rurais, e a própria sede da fazenda. Além de todo o patrimônio cultural existente na fazenda (Ferrão, 2007)

A arquitetura trouxe inovações para os espaços de beneficiamento do café uma vez que, no decorrer dos anos surgiram livros sobre a arquitetura rural que buscavam tornar mais eficazes o arranjo físico das edificações envolvidas no beneficiamento e armazenamento dos grãos, além das outras construções que compõe o espaço da fazenda e envolvem todo processo produtivo desde o plantio até o beneficiamento do fruto, abrangendo o produto e as pessoas envolvidas (Benincasa; Farah, 2020).

É nessa paisagem que o sujeito precisa entender o espaço para constituir seu senso de lugar, fica clara a importância da função da organização espacial do ambiente. Tal desempenho está atrelado tanto à capacidade de recepção dos usuários, quanto à disposição da arquitetura e do layout do lugar, uma vez que revelam o arranjo funcional gerador dos distintos fluxos empreendidos pelos vários usuários do projeto em questão. A sinalização, a configuração arquitetônica, o planejamento do 
layout, bem como, as inter-relações entre as áreas funcionais, formam "chaves de leitura" ambientais e têm efeitos primordiais para a orientação espacial dos indivíduos (Lynch, 2006).

Portanto, diante do conjunto que compõe a implantação de uma fazenda, depara-se com os atributos naturais da paisagem. O paisagismo produtivo pode ser descrito como a concepção de macro e micro paisagens com a intenção de cultivar alimentos, espécies medicinais, entre outras, garantindo a "estética ecológica" do ambiente que sofreu a intervenção antrópica. No caso particular do cafeeiro, as espécies de arbustos constituem um dos mais importantes elementos de composição paisagística, isso se deve especialmente a sua versatilidade de aplicação nas diferentes condições cênicas da paisagem. Na Fazenda Vidigal, o ambiente é inspiração para arte, uma análise espacial revela características singulares referentes a aspectos de qualidade estética e ambiental (Antônio, 2013).

Isso demonstra que a maneira de olhar para a paisagem rural merece uma atenção especial, ao analisar os atributos da paisagem, cada quadrante revela características peculiares em termos de beleza cênica local e seu potencial paisagístico, em função da presença de matas, conjunto de árvores, disposição das culturas agrícolas que formam o patrimônio cultural do lugar. Em quase toda a extensão da área analisada as plantações de café enriquecem a paisagem e contribuem para seu dinamismo.

As paisagens rurais são muito importantes para o reconhecimento da cultura nesta porção territorial. A conceituação das paisagens culturais está relacionada ao território das propriedades rurais por meio da inter-relação da paisagem natural com as edificações formadas ao longo da história, que formam o conjunto arquitetônico rural, que Argollo Ferrão (2004) define como "arquitetura rural". Atualmente, avaliando a necessidade de sustentabilidade, as fazendas não se resumem mais simplesmente ao meio agrário, com a valorização de todo o seu patrimônio e com a visão do turismo cultural no sentido de preservar paisagens, as fazendas tem o potencial de se tornar um complexo arquitetônico.

No que concerne ao arranjo físico da lavoura cafeeira o planejamento arquitetônico das instalações, equipamentos e pessoas que trabalham na empresa, objetivando o melhor desempenho dos agentes que compõem o processo produtivo. As plantações são distribuídas em renques com espaçamento planejado entre os troncos de café organizados em linhas e essas por sua vez, também possuem um espaçamento adequado que viabiliza o manejo (Marques, 2019).

Um fator de grande relevância diz respeito às variáveis ambientais, as quais são importantes para o estudo de campo, pois influenciam na implantação do café na propriedade. É pertinente apontar que por se tratar de uma análise de arquitetura rural, a fazenda recebe iluminação de maneira generalizada durante todo o período do ano, sem barreiras ou áreas a considerar diferenciadas pelo percurso do sol. Parte da implantação do café da fazenda Vidigal é feita entre renques de grevíleas (Grevillea robusta) que fazem o sombreamento da lavoura.

Fica evidente que a disposição dos renques do café é diretamente influenciada pela topografia do terreno e ventos predominantes. De acordo com o site WeatherSark, o município de Barra do Choça não possui cadastro específico dos dados de variáveis climáticas. Assim, utiliza-se para os ventos dominantes os dados referentes ao município cidade mais próximo cadastrado, assim, os ventos predominantes da região vêm do Leste, fator esse muito importante para o posicionamento dos quebra-ventos da lavoura (WeatherSark, 2021).

No arranjo paisagístico das plantas de café na fazenda Vidigal, os talhões, divisões da implantação da lavoura, são cultivadas variedades do café arábica que pode ser da mesma variedade ou não e nessas divisões geométricas da plantação há estágios de maturação distintos, fato este que é determinante para o processo e momento da colheita. O arranjo físico do cafezal é determinado ao mapear a região a implantar a lavoura e a disposição dos renques de café variam de acordo a topografia do terreno. O espaçamento das linhas, como representado no croqui da Figura 2, é feito a cada 3,30 m entre ruas de café por 0,5 m entre plantas, caule a caule. Esse arranjo paisagístico representa a 95\% da fazenda Vidigal, o restante do plantio, onde tem o cedro (Toona ciliata) que promove a arborização do cafezal, foi feita uma adaptação e as ruas são mais largas, em média com 3,70 m (David, et al, 2021). 
Figura 2 - Arranjo físico do cafezal.

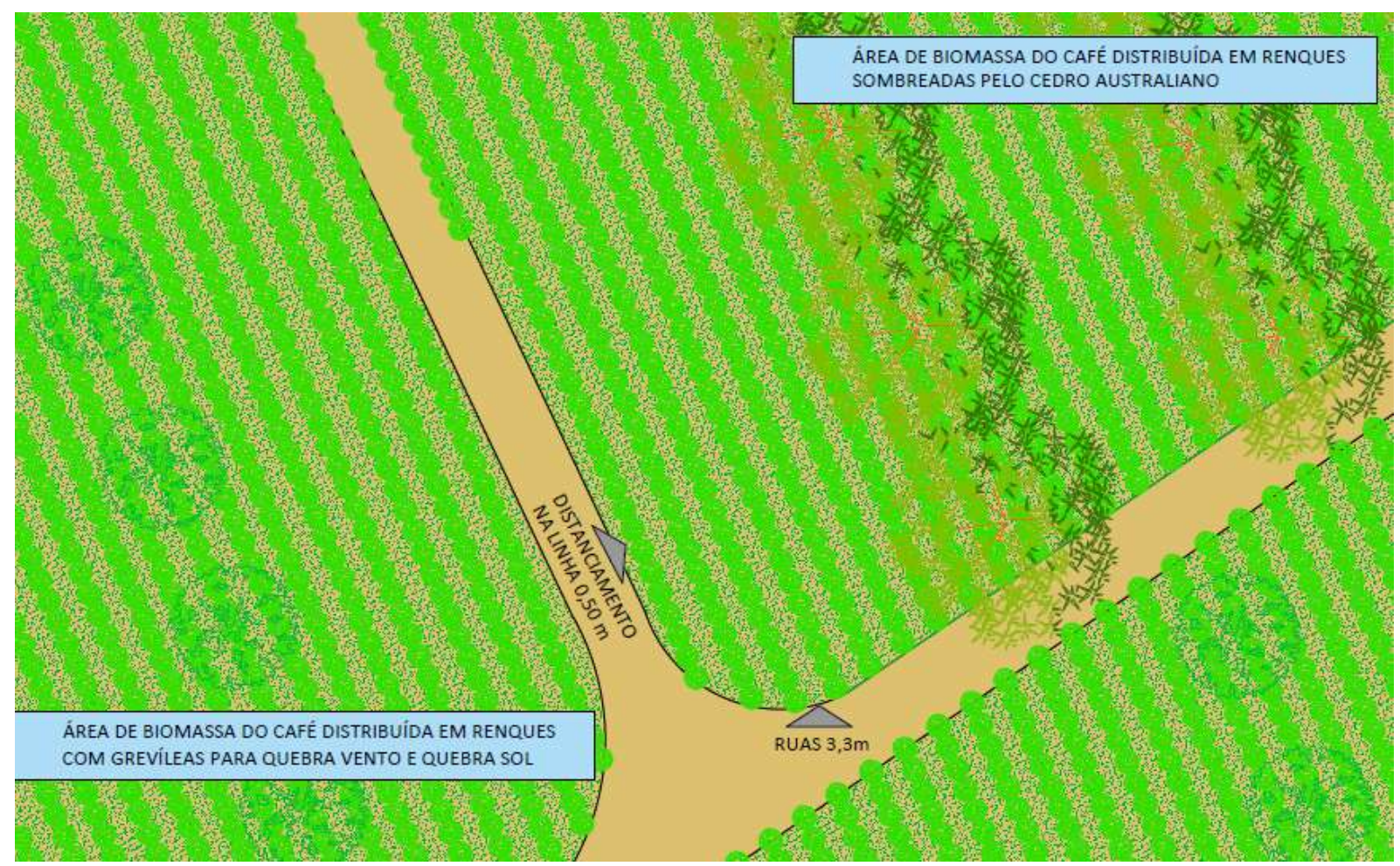

Fonte: Autores (2020).

A propriedade rural atrai um grande público, tanto os amantes do café, quando o público infantil, assim como o público científico, nela há um conjunto de elementos arquitetônicos e paisagísticos significativos que favorecem a composição estética dessas unidades de paisagem.

A fazenda, como mostra a Figura 3, além da plantação, tem área de lazer, espaço gourmet, auditórios, galeria de arte e esculturas gigantescas no meio do cafezal, um galpão com $140 \mathrm{~m}^{2}$ outro de galpão de $300 \mathrm{~m}^{2}$ (com 2 sanitários e 2 quartos para depósito) usado para palestras durante o Encontro Nacional do Café e para guardar as máquinas; auditório de $60 \mathrm{~m}^{2}$ com varanda; residência para colaborador; o museu do café; galeria de arte em um Container; Pomares; espaço gourmet com 300 $\mathrm{m}^{2}$; casa sede; matas preservadas; uma área em recomposição com plantio árvores nativas, e plantio de cedro-australiano. 
Figura 3 - Arranjo paisagístico da fazenda Vidigal.

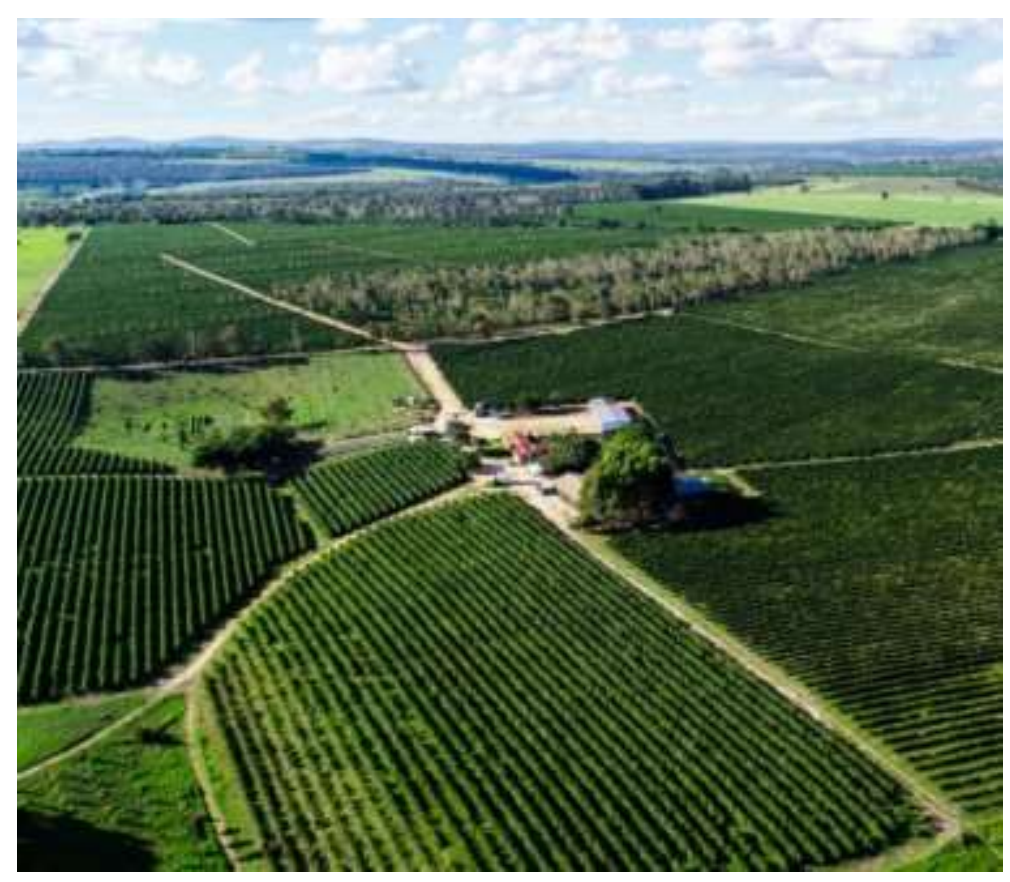

Fonte: Fazenda Vidigal (2019).

As propriedades de café do Planalto da Conquista têm investido no sombreamento dos cafezais com o objetivo de resolver a escaldadura (queima das folhas). A arborização altera as questões da radiação solar, do vento e da temperatura, promove um ambiente mais diverso do que a pleno sol, isso gera um manejo mais difícil em tese. A arborização com espécies e espaçamentos adequados pode apresentar resultados satisfatórios, quando comparado ao cultivo a pleno sol. Análises sobre o crescimento de plantas sombreadas dão suporte à busca da arquitetura ideal de cafeeiro, que maximize a captação da radiação solar disponível em ambientes sombreados.

Os estudos estão mostrando que apesar de ser comprovada essa variedade e heterogeneidade de luz e temperatura o comportamento dos pés de cafés é muito semelhante. Nos cafeeiros observados na fazenda Valeria Vidigal, os grãos que estão mais próximos da sombra estão menos vigorosos, o resultado esperado era o contrário. Esse fato pode estar relacionado ao adensamento das plantas de café, são 5 linhas de café e na linha o distanciamento de um pé para o outro é 0,5 m de distância. Como a planta está plantado muito junto (entre 0,5 e $0,75 \mathrm{~m}$ ) a mesma começa a regredir. Quando a plantação é arborizada o espaçamento (de tronco a tronco) na linha necessita ser de 1,0 m no mínimo, de acordo com as recomentações técnicas da cafeicultura para o Estado da Bahia (Martinez, et al, 2004).

Nem sempre a arborização funciona, alguns pesquisadores relacionam a qualidade do café em regiões de altitude à amplitude térmica, se o sombreamento vai diminuir essa diferença térmica, consequentemente irá alterar a qualidade esperada da safra do café. A introdução de árvores no interior do cafezal resulta em alterações sensíveis no microclima e de modo geral ocasiona a diminuição dos ventos, e redução das temperaturas máximas e aumento das temperaturas mínimas. As árvores e suas copas acima dos cafeeiros funcionam como anteparos que interceptam a radiação emitida pela superfície e emitem de volta, impedindo o excesso de resfriamento noturno e durante o dia há redução na temperatura nos períodos mais quentes (Matsumoto, 2003).

Nesse contexto fica clara a influência da expansão da lavoura cafeeira no desenvolvimento da arquitetura do espaço urbano e não urbano do município de Barra do Choça. A produção de café no município, conta com a Cooperativa Mista Agropecuária Conquistense (COOPMAC) onde os associados recebem apoio logístico e de mercado para escoar a produção (Coopmac, 2021). 


\section{Conclusão}

Com o estudo da implantação paisagística da cafeicultura na Fazenda Vidigal, pode-se afirmar que o arranjo paisagístico dos renques de café na fazenda é único porque o relevo é distinto, a temperatura e incidência de sol e ventos são singulares. Assim, o arranjo físico e paisagístico da plantação foi realizado especificamente para fazenda Vidigal e é baseado nas características edafoclimáticas de cada propriedade.

O agronegócio cafeeiro contribuiu para a expansão da cidade e do campo, gerando renda para os habitantes que foram atraídos pela cultura da biomassa do café, bem como para os grandes proprietários de terra, que receberam incentivos.

Da mesma forma, deve ser avaliado o sombreamento dos renques, dependendo da localização da propriedade o sistema consorciado pode favorecer e muito o desenvolvimento da lavoura e prevenção de problemas como a escaldadura e perda de produtividade.

Do mesmo modo que na arquitetura o layout de uma edificação é pensado para atender cada cliente individualmente, a partir do presente estudo, observou-se que a implantação da fazenda deve ser elaborada por uma equipe que envolve além da análise paisagística, a engenharia agronômica verificando as variáveis ambientais como topografia, temperatura, incidência solar, pluviosidade, ventos, tipo de solo e assim, surge um arranjo paisagístico singular para cada propriedade rural reduzindo os prejuízos trazidos pelas tentativas de implantação paisagística da lavoura sem sucesso.

O presente estudo mostra que com a analise do arranjo físico e paisagístico é possível estabelecer relações entre os vários espaços, a quantificação de insumos, mudas e levantamento dos custos da implantação de qualquer agronegócio. Contudo, vale salientar que essa pesquisa embasa um layout que pode ser utilizado em qualquer tipo de agronegócio.

\section{Agradecimentos}

Agradecemos os proprietários da Fazenda, Valéria Vidigal da Cruz Brito e Gianno de Oliveira Brito e a arquiteta Cristal Brito de Castro por contribuir para o sucesso desta pesquisa. Agradecemos também as Faculdades Santo Agostinho de Vitória da Conquista BA pelo apoio para o projeto de pesquisa intitulado "Arquitetura Rural: estudo da implantação das fazendas de café" que possibilitou aprofundar os resultados obtidos.

\section{Referências}

Antônio, M. T. B. (2013) Paisagismo produtivo. Ornamental Horticulture, v. 19, n. 1, p. 47-54.

Vianna, C. A. F. J. (2020) O café no Brasil do século XIX a partir do periódico "O Auxiliador da Indústria Nacional" (1833-1896). Tese (doutorado) Universidade Estadual de Campinas, Faculdade de Educação, Campinas, SP.

Benincasa, V. (2007) Fazendas paulistas: arquitetura rural no ciclo cafeeiro. Tese de Doutorado-Programa de Pós-Graduação em Arquitetura e Urbanismo e Área de Concentração em Teoria e História da Arquitetura e Urbanismo - Escola de Engenharia de São Carlos da Universidade de São Paulo.

Benincasa, V.; Farah, A. P. (2020) Arquitetura Rural nas Zonas Pioneiras de São Paulo: primeira metade do século XX. Revista Nacional de Gerenciamento de Cidades, V.8, $\mathrm{N}^{\mathrm{o}} 64$.

Brasil. (2020). Panorama das cidades. Instituto Brasileiro de Geografia e Estatística (IBGE).

Coopmac (2021). História da cooperativa. https://www.coopmac.com.br/a-coopmac/

David, A. M. T. F. S. et al. (2021). Arranjo físico e paisagístico da biomassa cafeeira na fazenda Vidigal: características edafoclimáticas influenciam no sucesso do agronegócio. International Journal of Development Research. v. 11, p. 44184-44188.

Fazenda Vidigal (2019) http://www.valeriavidigal.com.br/v1/fazendavidigal/.

Ferrão, A. M. A. (2004) Arquitetura do café. Campinas: Editora da Unicamp; São Paulo: Imprensa Oficial do Estado de São Paulo.

Ferrão, A. M. A. (2007) Arquitetura rural e o espaço não-urbano. Labor \& Engenho, Campinas.

Gil, A. C. (2010) Como elaborar projetos de pesquisa. 5. ed. São Paulo: Atlas. 
Research, Society and Development, v. 10, n. 7, e58310717003, 2021

(CC BY 4.0) | ISSN 2525-3409 | DOI: http://dx.doi.org/10.33448/rsd-v10i7.17003

Kohlhepp, G. (2020). Transformações da Paisagem Natural no Norte do Paraná entre as Décadas de 1930 e 1980: Da Monocultura do Café à Modernização Agrária e suas Consequências Ecológicas, Econômicas e Sociais. Historia Ambiental Latinoamericana Y Caribeña (HALAC) Revista De La Solcha, 10(2), 255-283.

Lynch, K. (2006) A Imagem da cidade. São Paulo: Martins Fontes.

Marques, J.R. (2019). O que é e quais são os tipos de arranjo físico. Goiânia: IBC.

Matsumoto, S. N. (2004) Arborização de cafezais no Brasil. Vitória da Conquista: Edições UESB.

Matsumoto, S. N. et al. (2003). Avaliação das condições hídricas de cafezais arborizados com grevíleas no município de Barra do Choça-Bahia. SBIcafé. Viçosa, MG

Nova, L. (2010) Café, a saga de um herói. Arte e Café! Do Planalto de Vitória da Conquista para o Mundo. Ilustração Valéria Vidigal. Salvador: Contexto e Arte Editorial Ltda.

Pereira A.S. et al. (2018). Metodologia da pesquisa científica. [e-book]. Santa Maria. Ed. UAB/NTE/UFSM.

Peruzzolo, M. C. et al (2019) Polinização e produtividade do café no Brasil. PUBVET, V. 13, n.4, p. 1-6

Rocha, L. O. (2011) Transformações na cidade de Barra do Choça/BA após a implantação da cafeicultura: uma análise da relação cidade-campo. 2011. Dissertação (Mestrado em Geografia) - Instituto de Geociências, Universidade Federal da Bahia, Salvador.

Slack, N.; Chambers, S.; Johnston, R. (2002) Administração da produção. Editora Atlas, São Paulo

Weatherspark (2021). Condições meteorológicas de Vitória da Conquista. https:o//pt.weatherspark.com/y/30889/Clima-caracter\%C3\%ADstico-emVit\%C3\%B3ria-da-Conquista-Brasil-durante-o-ano 